\title{
Una lectura semántica de la casida La Ceguera de Abu l-Majsi l-Andalusi
}

\section{A Semantic Reading of Abu l-Majsi l-Andalusi's Qasida The Bilndness}

\author{
D. Saeed MASFER AL-MALKI \\ Profesor Asistente Departamento de Lengua Árabe \\ Facultad de Letras y Humanidades Universidad Malik `Abd al- ${ }^{\circ}$ Aziz
}

Recibido: abril 2010

Aceptado: junio 2010

\section{RESUMEN:}

El objeto de este estudio es realizar una lectura semántica de la casida La ceguera de Abu l-Majsi alAndalusi, m. entre los años 180/796-206/822. Hemos dividido el artículo de la manera siguiente: Comenzamos con una introducción en que hablamos de los estudios de semántica y las principales tendencias que hay en este campo. A continuación, tres apartados: en el primer apartado se hace una presentación del poeta; en el segundo, se pretende arrojar luz sobre las diferentes dimensiones de la experiencia poética en Abu 1-Majsi, mientras que el tercero está dedicado a la lectura semántica del poema La ceguera, apartado que está dividido, a su vez, en otros tres: los significados del verbo, los significados del nombre y los significados de las partículas. Terminamos el artículo con una breve conclusión.

Palabras clave: Literatura y poesía de al-Andalus. Abu 1-Majsi al-Andalusi. Casida de La ceguera.

\begin{abstract}
This paper is concerned with the semantic connotations of lexis in "Blindness" a poem written by Abu 1-Makhshi al-Andalusi who died in the period ranging from (796 A.D and 180 A.H ) to( 822 A.D 206 A.H). The paper is divided into an introduction about the semantic connotations of lexis and the most outstanding trends in this field and the body which is divided into three sections: the first section gives background information about the poet, the second section sheds light on the different aspects of al-Makhshi's poetical career and the third section is devoted to reading the semantic connotations of the lexis in the poem in question. This last section is divided into three parts: the semantic connotations of the verb, the semantic connotations of the noun and the semantic connotations of the particles. The paper ends with a synopsis.
\end{abstract}

Key words: Literature and Poetry of al-Andalus. Abu Al-Majsi Al-Andalusi. Poem of the Blindness. 


\section{INTRODUCCIÓN}

En el pasado, el pensamiento árabe se ocupó de la semántica y de sus relaciones con la formación de significados diferentes dentro del texto. Esta preocupación no se limitó sólo a los críticos o a los lingüistas, sino que se extendió al círculo de los alfaquíes, de los ulemas de los fundamentos del derecho, de los exegetas coránicos, así como a los filósofos y a los lógicos ${ }^{1}$.

La cuestión de la palabra y el significado ha tenido una gran influencia en el avance del estudio de la semántica. Así, al-Yahiz (m. 255 H) se ocupa mucho de esta cuestión en su obra Al-Bayan wa-l-tabyin, donde hace de la palabra una de las más importantes significaciones que conforman el significado ${ }^{2} \mathrm{y}{ }^{\circ} \mathrm{Abd}$ al-Qahir al-Yuryani (m. $345 \mathrm{H})$ discute ampliamente esta cuestión tanto en Dala 'il al-i 'yaz como en Asrar al-balaga, extrayendo una valiosa teoría a este respecto, la teoría de la composición, en la que asegura que las palabras no tienen un significado en sí mismas, sino a través de aquellos elementos que se relacionan con ella dentro del contexto ${ }^{3}$. Con ello, lo que hace al-Yuryani es "relacionar el significado con la estructura".

En épocas más recientes, ha avanzado el estudio de la dimensión semántica, surgiendo en Occidente una nueva ciencia que se ocupa del significado y del estudio de sus diferentes dimensiones. Así, han destacado distinguidos científicos en el campo de la semántica -siendo quizá el principal Ferdinand de Saussure- con variados métodos de estudio dentro de esta ciencia, no quedándose sólo en los significados de las palabras dentro del texto, sino que fueron más allá, llegando a realizar estudios históricos de la evolución de las palabras y observando sus cambios semánticos a través de diferentes etapas históricas. Del mismo modo, llevaron a cabo estudios semánticos comparativos entre dos lenguas de una misma familia lingüística, además de otros estudios en nuevos campos de estudio dentro de la semánticas ${ }^{5}$.

También los estudiosos árabes modernos han realizado numeroso estudios dentro del campo de la semántica, beneficiándose del esfuerzo que hicieron los sabios árabes clásicos. Uno de ellos es el Dr. Muhammad Abu Musà, en su estudio Dalalat al-tarakib. También hay estudiosos árabes que han intentado aprovechar ambos aspectos: los estudios árabes clásicos y los estudios occidentales modernos, siendo, quizá, los más destacado el Dr. Tamam Hassan, en muchas de sus obras -de

\footnotetext{
${ }^{1}$ Véase, por ejemplo:
}

- En el campo de la crítica literaria: Ibn Atir, Al-Matal al-sa'ir fi adab al-katib wa-l-sa'ir, ed. Muhammad Muhyi 1-Din 'Abd al-Hamid, El Cairo, Matba'at al-Bani wa-l-Halabi, vol. 1, p. 197.

- En el campo de la lingüística: Abu Hilal al-Askari, Al-Furuq fi l-luga, Beirut, Dar al-Afaq al-Yadida, 1ª ed., 1973, p.130.

- En el campo del figh: Ibn Hazm, Al-Ihkam fi usul al-ahkam, Dar al-Afaq al-Yadida, 1ª ed., 1400H., pp. 38-40, entre otras.

- En el campo de los fundamentos del derecho: Al-Gazali, Al-Mustasfá fi 'ilm al-usul, Beirut, Dar al-Kutub al-'Ilmiyya, $2^{\text {a }}$ ed., 1403 H., vol. 1, pp.5.21.

- En el campo de la exégesis coránica: Abu Hayyan, Al-Bahr al-muhit, ed. 'Adil 'Abd al-Mawyud et al., Beirut, Dar al-Kutub al-'Tlmiyya, $1^{\mathrm{a}}$ ed., 1413 H., vol. 1, pp.105-121.

- En el campo de la filosofía y de la lógica: Ibn Rusd, Tahafut al-tahafut, ed. Sulayman Dunya, El Cairo, Dar al-Ma arif, $3^{\mathrm{a}}$ ed., 1968, pp. 105-186.

${ }^{2}$ Véase al-Yahiz, Al-Bayan wa-l-tabyin, ed. 'Abd al-Salam Harun, El Cairo, Maktabat al-Janyi, $4^{\mathrm{a}}$ ed., vol. 1, pp. $75-76$.

${ }^{3}$ Véase 'Abd al-Qahir al-Yuryani, Dala'il al-i'yaz, ed. Mahmud Sakur, El Cairo, Maktabat alJanyi, $2^{\text {a }}$ ed., $1401 \mathrm{H}$, vol. 1, pp. 36, 38, 43 y 57.

${ }^{4}$ Tamam Hassan, Al-Luga al-'arabiyya ma'na-ha wa-mabna-ha, El Cairo, Al-Hay'a al-'Amma li-1-Kitab, 1973, p. 187.

${ }^{5}$ Véase ‘Abd al-Karim Muyahid, Al-Dalala al-lugawiyya 'inda l-arab, Jordania, Dar al-Diya', 1985, pp. 11-18. 
las cuales la más importante es Al-Luga al-'arabiyya ma'na-ha wa-mabna-ha-, el Dr. Ibrahim Anis, en su libro Dalalat al-alfaz, y otros muchos.

En este estudio, vamos a procurar arrojar luz sobre el texto de la casida $L a$ ceguera, de Abu 1-Majsi al-Andalusi, centrándonos en la semántica. Para ello, vamos a aprovechar el esfuerzo previo que los antiguos árabes hicieron en este campo, sin descuidar el uso de algunos aspectos importantes en el campo de los estudios semánticos occidentales o de los estudiosos árabes modernos.

Este estudio presenta la habilidad que tiene el poeta andalusí Abu 1-Majsi para elegir los vocablos que son más adecuados para proporcionar unos significados fuertes y que son eficaces a la hora de dibujar unas dimensiones amplias y profundas de la experiencia de la ceguera que sufrió. Para ello, contará con un estudio lingüístico de las clases de vocablos empleados en la casida y cómo ello tiene como consecuencia la producción de unos significados que expresan profundamente su experiencia. En ocasiones, recurrimos a hacer comparaciones semánticas entre los vocablos empleados en el poema y otros que podrían ser usado en vez de aquellos, para llegar a conocer hasta qué punto el poeta ha sido capaz de utilizar los vocablos y de emplear su espacio semántico al servicio del significado poético.

Hemos dividido el estudio en tres partes, que son:

Primera parte: Presentación del poeta.

Segunda parte: La experiencia poética.

Tercera parte: La semántica en el poema La ceguera:

1) Los significados del verbo.

2) Los significados del nombre.

3) Los significados de las partículas.

\section{PRIMERA PARTE: PRESENTACIÓN DEL POETA}

Hay muchas fuentes históricas andalusíes clásicas que han tratado de la figura de Abu 1-Majsi al-Andalusi, coincidiendo todas ellas tanto en su nombre como en su nasab: 'Asim b. Zayd b. Yahyà b. Hanzala b. 'Alqama b. 'Adi b. Zayd b. Hammad al-Tamimi al-' 'Ibadi'. En cuanto a su kunya, las fuentes difieren, de manera que hay algunas que dicen que es Abu 1-Majsà', con alif maqsura, otras dicen que es Abu 1-Majsi ${ }^{8}$, con ya', e, incluso, Abu 1-Majsabi ${ }^{9}$, añadiendo una $b a^{\prime}$. También difieren en cuanto a la vocalización y puntuación de la kunya, de manera que algunos escriben Abu 1-Majassà ${ }^{10}$, con reduplicación en la sin maftuha y con alif maqsura, otras dicen Abu 1-Majassi ${ }^{11}$, con

\footnotetext{
${ }^{6}$ Véase, a título de ejemplo, Ibn al-Jatib, Al-Ihata fi ajbar Garnata, ed. Muhammad 'Abd Allah 'Inan, El Cairo, Maktabat al-Janyi, 1974, vol. 4, pp. 231-134; Ibn Zafir, Bada'i' al-bada'ih, ed.Muhammad Abu 1-Fadl Ibrahim, El Cairo, Dar al-Ma'arif, 1955, p 38.

${ }^{7}$ Véase al-Humaydi, Yadwat al-muqtabis fi dikr wulat al-Andalus, ed. Ruhiyya al-Suwayfi, Beirut, Dar al-Kutub al-'Ilmiyya, p. 363. Al-Humaydi lo incluye en el apartado "Bab man dukira bi-l-kunya", por lo que no he podido comprobar el nombre.

${ }^{8}$ Véase Ibn Sa'id, Al-Mugrib fi hulà al-Magrib, ed. Sawqi Dayf, El Cairo, Dar al-Ma arif, 1955, vol. 2, p. 141.

${ }^{9}$ Véase Ibn al-Jatib, Al-Ihata, vol. 4, p. 233.

${ }^{10}$ Véase Ihsan 'Abbas, Tarij al-adab al-andalusi: 'asr siyadat Qurtuba, Jordania, Dar al-Suruq, 1ª ed., 2001, p. 41.

${ }^{11}$ Véase 'Abd al-Gafur Ruzi, "Abu 1-Majassi al-Tamimi al-Andalusi: sa ir a ara sirata-hu l-tarij", al-Mayyalla al-'arabiyya li-l-'ulum al-insaniyya, Kuwait, no 75, año 19, verano 2001, p. 160.
} 
la ja' maftuha, y reduplicación de la sin maksura, o Abu 1-Majsi ${ }^{12}$, con sukun en la ja' y con ya', que es lo que me parece más correcto, puesto que en la casida La ceguera dice:

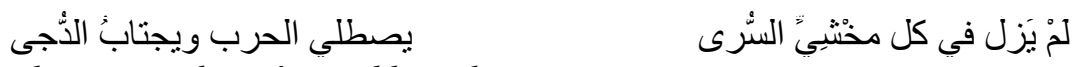

El hombre que, en los más terribles peligros, siempre encendía la guerra y atravesaba las tinieblas*.

Las fuentes tampoco se ponen de acuerdo en cuanto a su lugar de nacimiento y residencia en al-Andalus. Al-Humaydi, en su obra Yadwat al-muqtabis contradice al resto de autores, puesto que dice que "es árabe de casa y nacimiento, recorrió alAndalus como un extraño forastero" ${ }^{13}$, mientras que el resto de historiadores que han tratado acerca de Abu 1-Majsi afirma que "su padre entró en al-Andalus desde oriente, con el yund de Damasco y se estableció en la alquería de Sus; su hijo creció recitando poesía"14. Seguramente lo de "yund de Damasco" es una referencia a la campaña de Baly b. Bisr al-Qusayri, que atravesó el Estrecho hacia al-Andalus en el año $123 / 741$ para sofocar la revuelta de los bereberes ${ }^{15}$. Por ello, el nacimiento de nuestro poeta debió de producirse unos pocos años después de esta fecha.

En cuanto a su muerte, Elías Terés ya advirtió de la gran disparidad que hay en la fecha de su muerte, producto de la confusión que hay en el relato de Ibn Hayyan y que copia Ibn al-Jatib en su $I_{h a t a}{ }^{16}$. Unas veces, el relato dice que Abu l-Majsi llegó a vivir bajo el reinado del emir 'Abd al-Rahman II, entre los años 206/822 y 238/852 mientras que otras veces dice que su muerte se produjo en el año 180/796, en época de emir al-Hakam $I^{17}$.

Lo cierto es que esta ambigüedad también es recogida por Ahmad Haykal en su libro Al-Adab al-andalusi min l-fath ilà suqut al-jilafa ${ }^{18}$. En mi opinión, sólo con fijarnos en el poema que Hassana al-Tamimiyya (la hija de Abu 1-Majsi) recitó delante de al-Hakam I y en el que llora la muerte de su padre, sabríamos que la muerte de Abu 1-Majsi se produjo, sin ninguna duda, entre los años 180/796206/822, que son los que corresponden al reinado de al-Hakam I, tal y como ha indicado Ibn Sa id en Al-Mugrib $^{19}$, con lo que ya podemos descartar que la muerte de Abu 1-Majsi se produjera durante el reinado de 'Abd al-Rahman II:

\footnotetext{
${ }^{12}$ Véase Ahmad Haykal, Al-Adab al-andahusi min al-fath ilà suqut al-jilafa, El Cairo, Dar al-Ma`arif, 1979, $7^{\mathrm{A}}$ ed.,p. 98.

* Las traducciones de los versos - salvo indicación en contrario- las hemos tomado de Elías Terés, "El poeta Abu 1-Majsi y Hassana la Tamimiyya", Al-Andalus, XXVI, 1961, pp. 229-244.

${ }^{3}$ Al-Humaydi, Yadwat al-iqtibas, p. 363. Ihsan 'Abbas le apoya en esto cuando muestra su extrañeza porque Ibn Hazm, en su obra Fi fadl ahl al-Andalus, no menciona que Abu l-Majsi es uno de los que entraron en al-Andalus. Véase Ihsan 'Abbas, Tarij al-adab al-andalusi y véase, también, alMaqqari, Nafh al-tib, ed. Ihsan 'Abbas, Beirut, Dar Sadir, 1966, 2ª ed., p. 767.

${ }^{14}$ Ibn Sa'id, Al-Mugrib, vol. 2, p. 141. Véase, también, 'Abd al-Salam al-Harras, "Al-Sa ir 'Asim b, Zayd al-Tamimi (Abu l-Majsi)", Mayallat al-taqafa al-magribiyya, Rabat, no 9, 1973, p. 125.

${ }^{15}$ Véase Ibn 'Idari al-Marrakusi, Al-Bayan al-mugrib fi ajbar al-Andalus wa-l-Magrib, ed. G. S. Colin y E. Levi-Provençal, Beirut, Dar al-Taqafa, 1980, vol. 2, pp. 59 y ss.

${ }^{16}$ Elías Terés, "El poeta Abu l-Majsi y Hassana la Tamimiyya", Al-Andalus, XXVI, 1961, p. 240.

${ }^{17}$ Véase Ibn al-Jatib, Al-Ihata, vol. 4, p. 234.

${ }^{18}$ Ahmad Haykal, al-Adab al-andalusi, p. 99.

${ }^{19} \mathrm{Ibn}$ Sa id, Al-Mugrib, vol. 2, p. 124.
} 

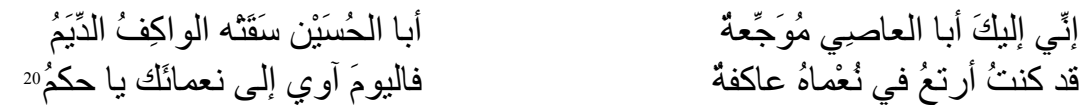

Vengo a ti,joh, Abu l-'Asi!, doliente por [ mi padre] Abu l-Husayn -jriéguelo una lluvia perenne!-.

Yo vivía en la abundancia, amparada en sus bondades, $y$ hoy vengo a acogerme en tus bondades, ;oh, al-Hakam!

Quien estudie la vida de Abu 1-Majsi encontrará que no fue una vida al margen de las páginas de la historia andalusí, sino que participó en la formación de algunos pasajes de la historia política de al-Andalus y los diferentes sucesos que tuvieron lugar en aquel entonces $^{21}$. A pesar de la parquedad de las fuentes históricas a la hora de transmitir su producción científica a lo largo de la historia debido al desarrollo de los sucesos políticos que acaecieron durante el reinado de 'Abd al- Rahman I y que no nos han conservado, de esta parte, más que un poema que recitó sobre la "batalla contra Abu l-Aswad al-Fihri, que fue una de las mayores conquistas del emir "Abd al-Rahman" ${ }^{22}$, ello no contradice lo que hemos dicho.

La mayoría de los libros de historia de al-Andalus señalan que Abu 1-Majsi se distinguió en el panegírico del emir Sulayman, hijo de 'Abd al-Rahman I ${ }^{23}$. Sin embargo, no deja de extrañarnos que estas fuentes no hayan recogido más que un poema en este campo que, por otro lado, ni siquiera está dedicado a él, sino que en su introducción hace un panegírico de su padre 'Abd al-Rahman I, elogiando la victoria sobre sus enemigos.

Los historiadores de la literatura han preferido ocuparse de un verso de uno de sus panegíricos al emir Sulayman en el que Abu 1-Majsi insinúa el estrabismo del príncipie Hisam:

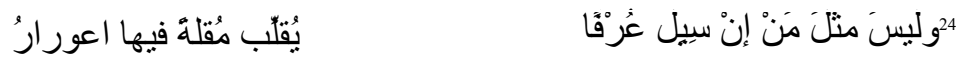

Ellos no son como aquel que, cuando se le pide un favor, desvía la vista, con mirada atravesada.

En mi opinión, este verso sólo refleja un aspecto de la naturaleza de la rivalidad entre los dos hermanos y no justifica el castigo ejemplar que posteriormente sufrió Abu 1-Majsi, al que se le sacaron los ojos y se le cortó la lengua. En mi opinión, si no hubiese sido por la gran rivalidad que existió entre los dos príncipes, nuestro poeta no hubiese sufrido tamaño castigo ${ }^{25}$.

\section{SEGUNDA PARTE: LA EXPERIENCIA POÉTICA}

Quizás, al hablar de la experiencia poética en Abu 1-Majsi no sea posible hacerlo en todos sus rasgos, exponiendo todas sus características, sobre todo

\footnotetext{
${ }^{20}$ Al-Maqqari, Nafh al-tib, vol. 4, p. 167.

${ }^{21}$ Véase 'Abd al-Gafur Ruzi, “Abu 1-Majassi al-Tamimi al-Andalusi”, pp. 117-158

${ }^{22}$ Ibn al-Jatib, Al-Ihata, vol. 4, p. 235.

${ }^{23}$ Idem, p. 234.

${ }^{24}$ Ibidem.

${ }^{25}$ Véase Ahmad Mujtaral-Tbadi, Fi tarï al-Magrib wa-l-Andahus, Alejandría, Daral-MÁrifa al-Yami iyya, 2005, pp.89-90.
} 
sabiendo que la experiencia poética significa un tipo de convivencia temporal entre la inspiración poética y algo que aparece en la experiencia vital del poeta ${ }^{26}$.

La falta de claridad de la experiencia poética en Abu 1-Majsi se debe a que no hay una producción abundante de su poesía porque las fuentes han transmitido poco o nada su poesía. Esto no quiere decir que descubrir algunos de sus rasgos sea algo imposible, puesto que muchas fuentes hacen referencia a la fuerza de la poesía de Abu 1-Majsi y a su capacidad para componer.

Así, por ejemplo, al-Humaydi, en al-Yadwa, hablando del valor de uno de los poetas de al-Andalus, Abu 1-Mutarrif, al que precedió el poeta Abu 1-Majsi, dice: "Fue uno de los mejores poetas que ha alumbrado al-Andalus; estuvo en estas tierras, entre Abu 1-Majsi e Ibn Darray"27. Y añade: "utiliza la técnica clásica de composición... uno de los grandes poetas del pasado" 28 .

Ibn al-Qutiyya describe a Abu 1-Majsi y a su poesía, diciendo: "[fue] el poeta de alAndalus en su época" ${ }^{\prime 2}$, que es lo mimo que dice el autor de Bada ' $i$ ' al-bada ' ${ }^{30}{ }^{30}$. Y dice Ibn al-Jatib en al-Ihata: "Fue un glorioso poeta" ${ }^{31}$. Por su lado, Ibn Sahid, en su libro Hanut 'attar declara el asombro que le producen los versos de Abu 1-Majsi en los que describe la noche ${ }^{32}$.

Si nos detenemos a estudiar lo que se nos ha conservado de la producción de Abu 1-Majsi, veremos que estamos ante un poeta que posee un elevado talento poético. El propio Abu Nuwwas se admiró del poema La ceguera: "Esto es lo que buscaban los poetas y no dieron con ello" ${ }_{33}$.

Del mismo modo, los estudiosos árabes modernos han elogiado la poesía de Abu 1-Majsi como destacada. Ahmad Haykal dice que "representa de la mejor manera la poesía andalusí en el período de fundación del emirato [...] Lo representa en cuanto a sus características andalusíes propias: la renovación de algunos temas, la preeminencia del elemento afectivo y la mejora del modo de expresión ${ }^{34}$.

Ihsan 'Abbas coloca su poesía dentro de la poesía beduina ${ }^{35} \mathrm{y}$ así la califica $\mathrm{M}^{\mathrm{a}}$ Jesús Rubiera Mata, al decir: "Es el primer poeta árabe que nació en al-Andalus y cuya poesía se distinguió por las características propias de la poesía árabe clásica" ${ }^{36}$. Por su parte, Elías Terés dice que su producción está en un grado elevado de calidad técnica y Ángel González Palencia lo sitúa en la vanguardia de los poetas de su tiempo ${ }^{37}$. Sin embargo, Emilio García Gómez lo sitúa con los poetastros que no posen ningún talento poético ${ }^{38}$. En mi opinión, ello se debe a que no profundizó en la producción de Abu 1-Majsi. Puede que la poesía de Abu 1-Majsi se le hubiese mostrado claramente si hubiese leído el gran

\footnotetext{
${ }^{26}$ Ménard, Réné, La experiencia poética, Caracas, Monte Ávila Editores, 1970, p.19.

${ }^{27}$ Al-Humaydi, Al-Yadwa, p. 99.

${ }^{28}$ Idem, p. 146.

${ }^{29} \mathrm{Ibn}$ al-Qutiyya, Tarij iftitah al-Andalus, ed. Ibrahim al-Abyari, El Cairo, Dar al-Kutub al-Islamiyya, 1982, p. 56.

${ }^{30}$ Ibn Zafir, Bada' $i$ ' al-bada'ih, vol. 1, p. 81.

${ }^{31}$ Ibn al-Jatib, Al-Ihata, vol. 4, p. 231.

${ }^{32}$ Al-Humaydi, Al-Yadwa, p. 146.

${ }^{33}$ Ibn Qutiyya, Tarij iftitah al-Andalus, p. 57; al-Zubaydi, Tabaqat al-nawiyyin wa-l-lugawiyyin, ed. Muhammad Abu l-Fadl Ibrahim, El Cairo, Dar al-Ma arif, 1973, p. 285.

${ }^{34}$ Ahmad Haykal, Al-Adab al-andalusi, p. 100.

${ }^{35}$ Ihsan 'Abbas, Tarij al-adab al-andalusi, p. 41

${ }^{36}$ Rubiera Mata, Ma Jesús, Literatura hispanoárabe, Alicante, Publicaciones de la Universidad de Alicante, 2004, p, 49.

${ }^{37}$ González Palencia, Ángel, Historia de la literatura arábigo-española, Barcelona, Editorial Labor, $2^{\mathrm{a}}$ ed., 1945, p. 53.

${ }^{38}$ García Gómez, Emilio, Poemas arábigoandaluces, Madrid, Espasa Calpe, 8a ed., 1985, p. 25.
} 
estudio de Elías Terés sobre Abu 1-Majsi. Este se centra en los vericuetos de la creación poética de lo que nos ha quedado de la producción poética de Abu 1-Majsi ${ }^{39}$.

La experiencia poética de Abu 1-Majsi se extiende a lo largo de numerosos temas poéticos, siendo el panegírico el más abundante, como señalan las fuentes históricas, como Ibn al-Jatib, quien dice acerca de Abu 1-Majsi: "Llegó a ser el poeta de al-Andalus y el panegirista de los omeyas, de quienes ha dejado extraordinarias rimas de poesía panegírica" ${ }^{40}$. Y vemos que hay dos casidas de Abu 1-Majsi de tema panegírico, la primera es aquel poema de diez versos que compuso con motivo de una de las victorias de Abd al-Rahman I y en el que alaba con intensidad a su hijo, el príncipe Sulayman. Este es su primer verso:

$$
\text { أودىَ بهم طلبُ الذب لم يقدر }
$$

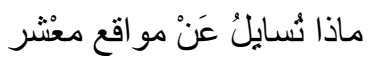

Si preguntan por la suerte de esta gente

y de sus secuaces, que pretendían lo imposible

En cuanto al segundo ponegírico, es la casida La ceguera, que es el tema de este estudio. Son, aproximadamente, quince versos. Ibn al-Jatib ha dicho que el número de sus versos era mayor ${ }^{42}$. Comenzaba con una introducción acerca de la ceguera y concluía con un panegírico a ${ }^{`} \mathrm{Abd}$ al-Rahman $\mathrm{I}^{43}$. Mientras que el resto de la producción de Abu 1-Majsi que se ha conservado no sobrepasa unos pocos fragmentos que se destacan (la mayoría) por una alta calidad técnica. Son los siguientes:

1- Sátira: Un verso contra el príncipe Hisam:

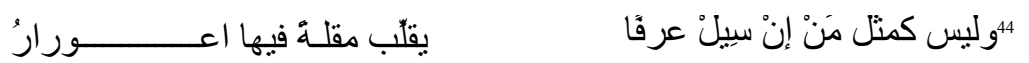

Ellos no son como aquel que, cuando se le pide un favor,

desvía la vista, con mirada atravesada.

Sátira contra Ibn Hubayra ${ }^{45}$ :

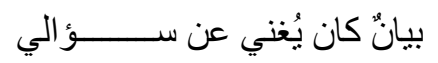

46 بألتِ و عندَ أمك من ختاني

Has preguntado y con tu madre hay una prueba de mi circuncisión

2- Queja: que hace inncesaria mi pregunta
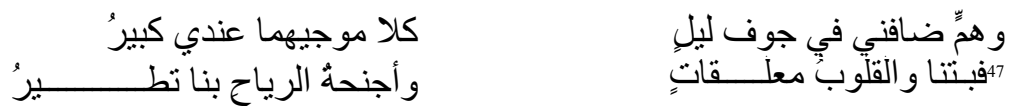

¡Cómo me cometió la angustia, en medio de aquel mar, y qué impresionanate fue para mí el oleaje de laangustia y del mar!

\footnotetext{
${ }^{39}$ Terés, Elías, "El poeta Abu -1-Majsi y Hassana la Tamimiyya”, Al-Andalus, XXVI, 1961, p.232.

${ }^{40}$ Ibn al-Jatib, Al-Ihata, vol. 4, p. 231.

${ }^{41}$ Idem, p. 234.

${ }^{42}$ Ibidem.

${ }^{43}$ Veremos la casida con detalle más adelante.

${ }^{44}$ Ibn al-Jatib, Al-Ihata, vol. 4, p. 234.

${ }^{45}$ Poeta andalusí, contemporáneo de Abu l-Majsi. Véase su biografía en Ibn Sa id, Al-Mugrib, vol. 2, p. 123.

${ }^{46}$ Ibidem.

${ }^{47}$ Al-Humaydi, Yadwa, p. 363.
} 
Pasamos la noche con el corazón acongojado, mientras las alas del viento nos llevban volando.

Y:

$$
\text { خُفية زفتِّ بين قادمنَي نِسر }
$$

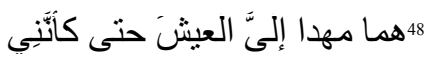

Ellos dos me han hecho tan muelle la vida, que me parece

estar reposando sobre el suave plumón que el águila lleva entre las alas. Y:

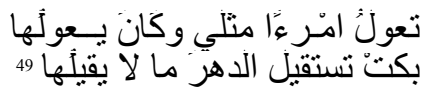

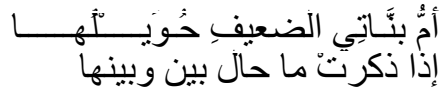

La madre de mis niñitas, su estado debilito*, sustenta a un hombre como yo, que antes la sustentaba.

Cuando ella lo que se ha interpuesto entre los dos,

llora, pidiendo al Destino que anule lo que no puede anular.

Con una rápida mirada a la producción poética de Abu 1-Majsi que precede, vemos que su poesía tiene un nivel elevado evidente. Las imágenes técnicas y los significados poéticos son destacados, especialmente en la casida La ceguera. Habalaremos de las dimensiones de su experiencia en el siguiente apartado. Del mismo modo, los versos de queja rebosa de imágenes bellas y construcciones creativas -que seguramente son la experiencia del poeta con la calamidad de la ceguera- y que participan con instensidad para elevar el nivel de la calidad de sus contenidos y de sus formaciones técnicas ${ }^{50}$. En los dos últimos versos sentimos "cuánto siente el poeta su desgracia., cómo había sido y cómo era ahora. Aquí está la esposa, la madre de las niñitas, en diminutivo, no de las niños, su estado debilito, también en diminutivo, al que mantiene después de que él la hubiera mantenido, llorando y pidiendo al destino que anule el tropiezo de su marido, para que vuelva a ser como era, lo cual es imposible"s1.

Por su parte, los dos versos de sátira que compuso Abu 1-Majsi reflejan su dominio y habilidad en esta arte poética ${ }^{52}$ y es la causa de que le cortaran la lengua y le vaciaran los ojos cuando ridiculizó al príncipe Hisam. Abu 1-Majsi, a pesar de las acusaciones que se le hicieron de ser cristiano, golpea a su adversario con versos hirientes. Parece que con ello conduce en al-Andalus el arte de la rivalidad poética o lo que se conocía en aquel tiempo como el arte de los poemas polémicos (fann al-naqa 'id). Por desgracia, las fuentes no nos han proporcionado más poemas suyos compuestos en este estilo.

\section{TERCERA PARTE: LA SEMÁNTICA EN LA CASIDA LA CEGUERA}

\section{LA CASIDA LA CEGUERA}

En mi opinión, el poema La ceguera de Abu 1-Majsi es uno de los poemás más destacados de entre todos los que se compusieron a comienzos del período andalusí. Abu

${ }^{48}$ Ibidem.

${ }^{49}$ Ibn al-Qutiyya, Tarij iftitah al-Andalus, p. 57.

* Modificamos la traducción de Elías Terés.

${ }^{50}$ Véase Ahmad Haykal, A-ladab al-andalusi, p. 100; al-Humaydi, Yadwat al-muqtabis, p. 146.

51 'Abd al-Razzaq Husayn, Al-I'aqa fi l-adab al-'arabi, al-Sariqa, Mansurat Madinat al-Sariqa li-1Jadamat al-Insaniyya, $1^{\text {a }}$ ed., 1999 , p. 81.

${ }^{52}$ Ibn al-Jatib, Al-Ihata, vol. 4, p. 231. 
Nuwwas lo calificó diciendo que "esto es lo que buscaban los poetas y no dieron con ello"s3. Ahmad Haykal califica el tema del poema de nuevo tema que ningún poeta antes de Abu 1Majsi había tocado ${ }^{54}$. 'Abd al-Razzaq Husayn se opone a esta opinión, asegurando que hubo anteriores a Abu 1-Majsi, apoyándose, para ello, en un grupo de poetas anteriores a Abu 1Majsi que describían los diferentes defectos y enfermedades que sufrían ${ }^{55}$. Sin embargo, al mismo tiempo asegura que "la experiencia de Abu 1-Majsi es una de las experiencias originales de nuestra literatura árabe que confirman su autenticidad, su sinceridad y su capacidad de tratar los aspectos tantos aparentes como encubiertos del alma humana" ${ }^{\text {. }}$. De ella dice 'Abd al-Salam al-Harras que es "el fragmento inmortal en el que ha descrito su ceguera y través del cual muestra instantáneas de su tragedia y de la de su familia"s7.

El nacimiento de este poema se produce después de una experiencia real que vivió Abu 1-Majsi. Los capítulos de su tragedia los escribió el príncipe Hisam, hijo de 'Abd al-Rahman I, quien quiso vengarse de la sátira que le había hecho Abu 1Majsi cortándole la lengua y vaciándole los ojos a causa del famoso verso:

$$
\begin{aligned}
& \text { يُقلّب مقلة فيها اعورار }
\end{aligned}
$$

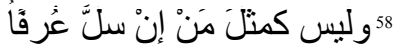

Ellos no son como aquel que, cuando se le pide un favor, desvia la vista, con mirada atravesada.

Realmente me ha gustado mucho lo que escribió Elías Terés acerca de lo deleznable de la acción de Hisam, cuando dice que "es penoso creer que una orden tan cruel saliera de labios del príncipe Hisam, al que pintan las crónicas adornado de toda clase de virtudes, de una bondad y generosidd extremadas, de un carácter tan dulce y afable que por el mereció el sobrenombre de al-Ridà (el bondadoso) ${ }^{59}$.

Ahora vamos a procurar dejar de hablar de la tragedia que dibuja la casida $L a$ ceguera mediante imágenes poéticas muy emotivas y con connotaciones destacadas cuyos rasgos conforma la habilidad de Abu 1-Majsi para seleccionar los vocablos que es de lo que va a tratar este estudio en las páginas siguientes- para estudiar los componentes del poema y sus diferentes elementos.

Ibn al-Jatib cita en al-Ihata -que es la ínica fuente qyue ha transmitido la versión más larga del poema La ceguera- que el poema es largo, pero se limita a escribir sólo quince versos, faltando el primer hemistiquio del verso octavo ${ }^{60}$. Mientras que alZubaydi, en Tabaqat al-nahwiyyin, añade un verso más cuyo significado no es correcto, como señala Elías Terés ${ }^{61}$, concretamente en su primer hemistiquio:

\footnotetext{
${ }^{53}$ Ibn al-Qutiyya, Tarij iftitah al-Andalus, p. 57.

${ }^{54}$ Ahmad Haykal, A-ladab al-andalusi, p. 87.

55 'Abd al-Razzaq Husayn, Al-I'aqa, p. 206.

${ }^{56}$ Idem, 207.

${ }^{57}$ 'Abdal-Salamal-Harras, “Al-Sa ir 'Asimb,Zaydal-Tamimi(Abul-Majsi)”, Mayallat al-Manahil, Rabat,no 5, 1976, p. 235.

${ }^{58}$ Ibn al-Jatib, Al-Ihata, vol. 4, p. 234.

${ }^{59}$ Terés, Elías, "El poeta Abu 1-Majsi”, p. 235.

${ }^{60}$ Ibn al-Jatib, Al-Ihata, vol. 4, p. 234.

${ }^{61}$ Terés, Elías, "El poeta Abu 1-Majsi”, p. 237.
} 
He sido las cumbres a las cumbres

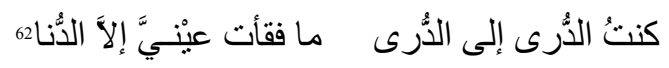
no sacó mis ojos mas que este mundo

Abu 1-Majsi comienza la casida con una introducción en la que se queja de su tragedia con la ceguera e imágenes del sufrimiento de su familia y de lo que le aconteció después de que él perdiera la vista. Ello ocupa doce versos, siendo los otros tres un panegírico a ${ }^{`}$ Abd al-Rahman I. Los versos del poema son:
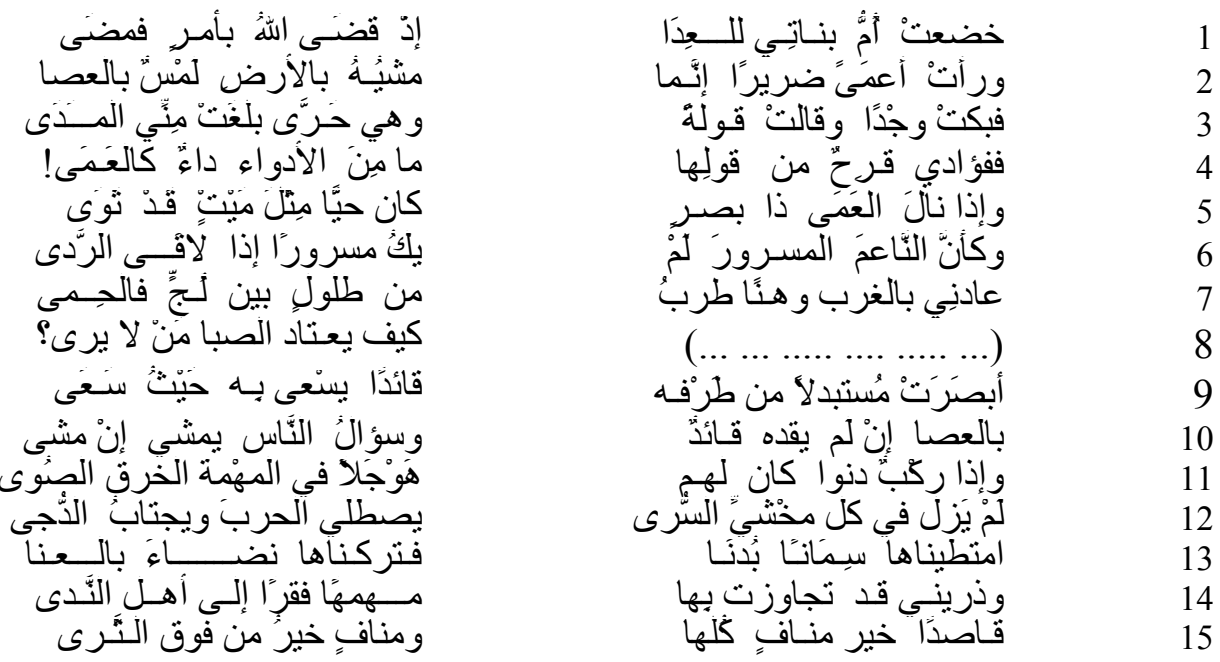

1 La madre de mis hijas se ha sometido a la adversidad pues Dios dictó una sentencia que se ha cumplido.

Ahora ella ve a un ciego, que sólo camina por la tierra a tientas con su báculo;

y llora dolorida; y pronuncia palabras con voz ferviente, que llegan a lo más hondo de mi ser.

Mi corazón se desgarra cuando ella me dice: jentre todas las desgracias no hay una mayor que la ceguera!

5 Cuando la ceguera sobreviene a un hombre que antes vio, queda-aunque vivo-sepultado;

$y$ aquel que disfruta de una vida alegre y dulce deja de estar alegre cuando se encuentra con la muerte.

Todas las noches, aquí en Occidente, me asalta la nostalgia recordande a los que viven entre Layy y al-Himà ¿cómo puede habituarse a la frivolidad un hombre que no ve?

Ella contempla a un hombre al que cambiaron sus ojos por un lazarillo que lo conduce a donde quiere ir;

10 y si no hay lazarillo que lo lleve, va con el bastón,

${ }^{62}$ Al-Zubaydi, Tabaqat al-nahwiyyin, p. 265; al-Qifti, Inbah al-ruwat alà anbah al-nuhat, El Cairo, Dar al-Fikr al-'Arabi, $1^{\mathrm{a}}$ ed., 1986, vol. 2, p. 366. 
suplicando a las gentes que lo guien, cuando quiere caminar,

Antes, cuando venían las caravanas, era para ellas

el hombre fuerte que las guiaba en el desierto interminable;

el hombre que, en los más terribles peligros,

siempre encendia la guerra y atravesaba las tinieblas.

Montábamos [los camellos] gordos y briosos,

y los dejábamos flacos, extenuados de fatiga.

¡Déjame! Con ellos he atravesado los desiertos

en busca de la gente de la generosidad,

15 encaminándome al hombre mejor de toda la estirpe de Manaf,

y Manaf es lo mejor que existe sobre la tierra*.

\section{LA SEMÁNTICA DEL POEMA}

En la introducción de este estudio expuse, en rápidos trazos, el interés que ha mostrado el pensamiento árabe por los vocablos y la semántica así como el interés que por este tema han tenido los estudiosos de la literatura, tanto clásicos como modernos.

En realidad, no quiero convertir este artículo en una profundización en el estudio de la semántica del poema La ceguera según la teoría de los campos semánticos, sino que me limitaré a aquello que es suficiente para conseguir los objetivos de este estudio que giran, como ya he dicho anteriormente, en torno a la capacidad y a la habilidad del poeta para elegir las palabras adecuadas para dibujar su trágica experiencia con la ceguera.

Los estudiosos en el ámbito de los campos semánticos han dispuesto algunos métodos que ayudan a comprender la mayoría de las connotaciones dentro del texto poético. Así, por ejemplo, se muestra su interés por descomponer el significado en sus elementos constitutivos y que lleva a cabo el estudio del "significado de cada palabra y la relación de cada una con las demás" ${ }^{63}$.

También la psicología del lenguaje participa de forma activa en el apoyo al estudio de la semántica en el texto poético mediante su interés por el estudio de "las intenciones del hablante al nivel de la superficie del discurso en forma de señales lingüísticas que se funden en el lenguaje" ${ }^{64}$.

El poeta creativo cuando emplea las palabras en la construcción del lenguaje de su poesía es absolutamente consciente de que abandona el sistema lingüístico habitual de diferentes sentidos para ir a otro sistema "en el que puede llevar a cabo la adecuación entre sus realidades sicológica, intelectual y social de manera simbólica" ${ }^{65}$ y pasa con cada una de sus palabras a lugares y significados que no

\footnotetext{
${ }^{*}$ Hemos modificado la traducción de Elías Terés.

${ }^{63}$ Ahmad Mujtar 'Umar, "Min al-ittiyahat al-hadita fi dirasat al-ma nà, tahlil al-kalimat ilà mukawwanat wa-'anasir", Al-Mayalla al-'arabiyya li-l-'ulum al-insaniyya, Kuwait, nº 3, vol. 1, 1981, p. 18.

${ }^{64}$ 'Abd al-Salam al-Misaddi, Qira'at ma'a l-Sabbi wa-l-Mutanabbi wa-l-Yahiz wa-Bn Jaldun, Kuwait, Dar Su'ad al-Sabah, $4^{\text {a }}$ ed. 1993 , p. 69 ,

${ }^{65}$ 'Abd al-Muna'im Talima, Madajil ilà 'ilm al-yamal al-adabi, El Cairo, Dar al-Taqafa, 1978, p. 114.
} 
habían sido destinados para esas palabras ${ }^{66}$. Sus palabras se desvían de su original disposición, buscando nuevos horizontes con un fin artístico y estético ${ }^{67}$.

Al observar la casida La ceguera de Abu 1-Majsi nos encontramos con que los vocablos empleados por el poeta no se quedan sólo en los límites de los significados que se les atribuyen, sino que tienen dimensiones y espacios semánticos propios que reflejan la habilidad y la capacidad del poeta para cosntruir su lenguaje poético. Además, participan activamente en la creación de imágenes que expresan muy bien su sufrimiento psicológico y el sufrimiento de su familia con la experiencia de la ceguera que ha padecido.

A lo lardo de este estudio intentaré descubrir los significados artísticos del léxico de la casida y que podemos estudiar alrededor de tres ejes: los significados de los verbos, los significados de los nombres y lossignificados de las palabras.

\section{1 LOS SIGNIFICADOS DE LOS VERBOS}

Abu al-Majsi consigue emplear la energía semántica de los verbos usados en el poema La ceguera de manera que refleje la profundidad de su sufrimiento y de la desgracia que ha padecido, del mismo modo que refleja su habilidad técnica. Podemos, en este punto, arrojar luz sobre los significados que encierran los verbos usados en el poema La ceguera mediante el estudio de sus significados según el tipo de verbo y las posibilidades de signifidos abstractos que proporciona cada verbo.

Para ver la tipología de los verbos usados en la casida La ceguera, hemos realizado la siguiente estadística:

\begin{tabular}{|l|l|}
\hline Tipo de verbo & $\mathrm{N}^{\mathbf{0}}$ de veces \\
\hline Perfectivo & 19 \\
\hline Imperfectivo & 9 \\
\hline Imperativo & 1 \\
\hline Total & 29 \\
\hline
\end{tabular}

Lo que podemos observar es que la mayoría de los verbos están en perfectivo, hasta en diecinueve ocasiones. Los verbos son: jada'a (se sometió), ra'à (vio), bakà (lloró), qala (dijo), absara (vio), qadà (juzgó), madà (pasó), sa à (caminó), masà (caminó), nala (dañó), kana (fue), tawà (sepultó), balaga (llegó), laqà (encontró), 'ada (volvió), tayawaza (pasó), dana (se acercó), imtatà (montó), taraka (dejó).

En segundo lugar, está el verbo en imperfectivo, con nueve veces. El imperativo sólo aparece en una ocasión. Sin ninguna duda, esto nos proporciona una clara indicación de que Abu 1-Majsi no puede librarse ni de la influencia que tiene la desgracia de la ceguera ni de las consecuencias dolorosas que la acompañan. Seguramente, esto está claramente representado en este verso:

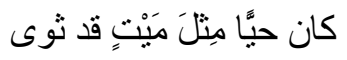

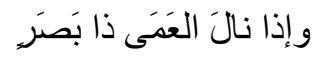

${ }^{66}$ Véase 'Abd al-Qahir al-Yuryani, Asrar al-balaga, qara'a-hu wa-'allaqa 'alay-hi Mahmud Sakir, El Cairo, Matba at al-Madani, $1^{\mathrm{a}}$ ed., 1991, p. 352. Véase, también, 'Abd al-Qahir al-Yuryani, Dala'il al-i'yaz, p. 262.

${ }^{67}$ Hasan Tabal, Al-Ma 'nà fi l-balaga al-'arabiyya, El Cairo, Dar al-Fikr, $1^{\text {a }}$ ed., 1998, p. 86. 
Cuando la ceguera sobrevive a un hombre que antes vio, queda-aunque vivo- sepultado;

Junto a esta presencia dominante del verbo en perfectivo, encontramos que Abu 1-Majsi usa el imperfectivo en nueve ocasiones: yakun (es), ya 'tadu (se acostumbra), yarà (ve), yas à (camina), yaqudu (conduce), yamsi (camina), yazal (deja de ser), yastali (se calienta), yaytabu (atraviesa). Podemos observar, por el contexto del poema, que la mayoría de estos verbos en imperfectivo dibujan la realidad del estado doliente del poeta después de haber perdido la vista, a excepción del verbo yakun, que devuelve al poeta a los días de la alegría pasada:$$
\text { يَكُ مسرورًا إذا لاقى الرَّدى }
$$
y aquel que disfruta de una vida alegre y dulce

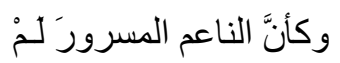
deja de estar alegre cuando se encuentra con la muerte.

Del mismo modo que la mayoría de los sentidos que reflejan estos verbos en imperfectivo son de movimientos que el poeta no puede llevar a cabo puesto que ha perdido muchas aptitudes a causa de la ceguera, como, por ejemplo, los verbos: yarà (ve), yas'à (camina), yaqudu (conduce), yamsi (camina), yaytabu (atraviesa).

En cuanto al imperativo, sólo aparece en la casida, como ya hemos dicho, una vez, en el verso:

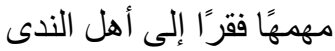
¡Déjame! Con ellos he atravesado los desiertos en busca de la gente de la generosidad

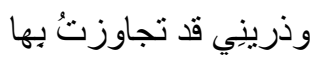

Esta orden no es más que un ruego que el poeta dirige a su esposa con cuyo estado de angustia y desánimo comienza el matla ${ }^{\prime}$ de este poema. No es una orden que se origine desde una posición de fuerza, sino que procede de un poeta que siente la debilidad y que nota cómo ha perdido la esperanza.

Al observar cómo ha empleado Abu l-Majsi los verbos (perfectivo, imperfectivo e imperativo) vemos que el poeta oscila entre el tiempo pasado y el tiempo presente, sin señalar en ningún momento al futuro, al que los sentimientos de frustración y de desesperanza le impiden aparecer en la construcción lingüística del poema.

El poeta tiene mucho cuidado a la hora de escoger el tipo de verbo con el que poder expresar el alcance de su sufrimiento a causa de la ceguera. Este sufrimiento es el que, según muchos estudiosos de la literatura, participa en "el afloramiento dulce, elegante, intencionado, de su poesía y que representa en sus poemas veraces imágenes sentimentales, a través de las cuales logra emocionar, mostrar y expresar en detalle sus sensaciones"68.

Para explicar la capacidad de Abu 1-Majsi y el cuidado que tiene en la elección de los verbos que dibujan significados que expresen su sufrimiento, nos detendremos junto a los verbos más significativos que se utilizan en el poema $L a$

\footnotetext{
${ }^{68} \mathrm{Nafi}^{e}$ Mahmud, Ittiyahat al-si'r al-andalusi ilà nihayat al-qarn al-talit al-hiyri, Bagdad, Dar alSu'un al-Taqafiyya al-'Amma, 1ª ed., 1990, p. 49.
} 
ceguera y que tienen un espacio de significación amplio y extenso. Veamos el primer verso de la casida:

$$
\text { إد قضى اللهُ بأمر فمضى }
$$

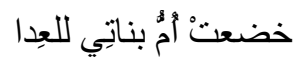

La madre de mis hijas se ha sometido a la adversidad pues Dios dictó una sentencia que se ha cumplido

Observamos en este verso la presencia de tres verbos, que son: jada' $a$ (someterse), qadà (dictar) y madà (cumplirse). Abu 1-Majsi comienza con el verbo jada'a, intentando llegar al grado más alto de debacle interna y de debilidad al que ha llegado a causa de la ceguera. No encuentra nada mejor que el verbo jada $a$ para expresar con fuerza el sentido que quiere. Además, le siguen otros dos verbos, qadà y madà. A pesar de que el primero de ellos indica su conformidad con lo que Dios ha decretado, este verbo, junto al verbo madà, incluyen tanto un significado connotativo relacionado con la velocidad a la que sobreviene la desgracia y la turbación que le produce como su falta de deseo para recordar sus dolorosos detalles.

También vemos la habilidad de Abu 1-Majsi a la hora de utilizar las energías connotativas de los verbos usados en su poema mediante el empleo de los verbos ver $\left(r a^{\prime} a ̀\right)$ y mirar (absara) en:
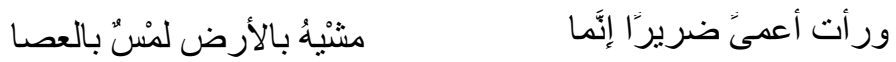

Ahora ella ve a un ciego que sólo

camina a tientas por la tierra con su báculo

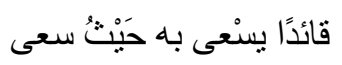

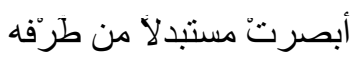

Ella contempla a un hombre al que cambiaron sus ojos por un lazarillo que lo conduce a donde quiere ir

El sujeto de ambos verbos es su esposa. Abu 1-Majsi no quiere detenerse en lo que se ve sólo con los ojos, sino que intenta añadir un sentido connotativo relacionado con una visión mental que se dibuja en la mente de la esposa y que es que ella ahora está delante de un marido ciego que no puede mantenerla ni a ella ni a sus hijas. Esto, sin embargo, no es algo que se pueda deducir del otro verso, en el que aparece el verbo absara.

El poeta creativo comprende perfectamente, con su sentido artístico, que conseguir darle una profundidad connotativo-expresiva a su poesía no se produce sólo mediante una ingeniería de los vocablos y diseñando moldes, sino que es necesario que ello sea acompañado por una construcción de las ideas, los sentimientos y las emociones del alma $^{69}$. Por ello, no pretendemos en este estudio confirmar la habilidad de Abu 1-Majsi para componer los significados de las palabras de su poema sin la presencia de un sentimiento veraz y de una experiencia poética real. Si volvemos a examinar los dos versos anteriores, veremos la habilidad del poeta a la hora de emplear el significado connotativo para el verbo $s a$ 'à en la imagen tanto del pasado como del presente. Se ayuda de este verbo para construir el significado connotativo cuando le acompañaba alguien que le conducía a donde quería. Con ello, se amplia el espacio en el que se

\footnotetext{
${ }^{69}$ Muhammad Abu Musà, Dalalat al-tarkib, El Cairo, Maktabat Wahba, 2a ed., 1987, p.171.
} 
mueve el poeta y que confirma repitiendo el verbo dos veces. Y esto es lo que no encontramos en el otro verso, donde sus movimientos se limitan a caminar y lo hace despacio y con dificultad, no le ayuda más que un bastón que ni entiende ni razona. Esta dimensión de significado la confirma, también, en el verso siguiente:

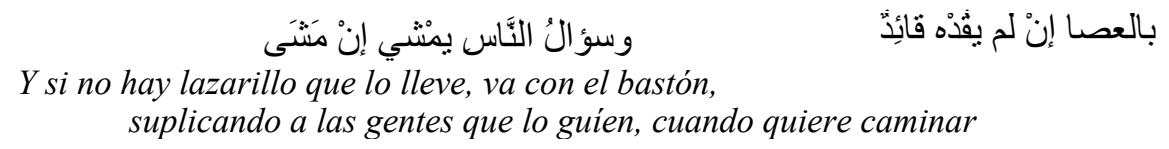

En los versos tercero y quinto de la casida nos aparecen cinco verbos: bakà (llorar), qala (decir), balaga (llegar), nala (dañar) y tawà (sepultar). Podemos detenernos ante los significados de tres de ellos: bakà (llorar), balaga (llegar) y nala (dañar) que añaden significados particulares al contexto poético. El uso que hace Abu l-Majsi del verbo bakà otorga el significado de dolor continuo en la esposa, herida por la cegera del marido, sostén de sus hijos. El verbo refleja también la profundidad de su dolor. Para ello, le añade a continuación "dolorida" (wayd $\left.{ }^{a n}\right)$ en vez de "con lágrimas" (dam $\left.{ }^{a n}\right)$, porque el dolor penetra su corazón. Este significado connotativo no lo puede dibujar otro verbo, como "gritar" (saraja). Del mismo modo, el uso que hace del verbo "llegar" (balaga) es muy apropiado para representar el sentido de la fuerza de la emoción que siente el poeta por las palabras que provienen de su esposa. Balaga es llegar hasta el final. En cuanto al empleo del verbo nala para referirse a la ceguera que sufre hay que decir que es muy acertado, porque nala es destruir algo por completo y esta destrucción, además, no proviene más que del enemigo. Esto es un sifnificado connotativo que no puede dibujar otro verbo, como, por ejemplo, atà. Este verbo nos refleja una dimensión semántica sobre el poder de la ceguera que nos representa Abu 1-Majsi bajo la forma de enemigo de su vista. No posee ninguna esperanza de volver a ver.

\subsection{LOS SIGNIFICADOS DE LOS NOMBRES}

El poema La ceguera reúne muchos ejemplos que demuestran la habilidad y la capacidad del poeta para emplear las posibilidades técnicas que proporciona el uso del nombre y de sus diferentes formas para apoyar la vertiente semántica del poema. Aquí vamos a intentar descubrir los rasgos semánticos más destacados que proporcionan dichas formas y aspectos de los diferentes nombres. Comenzaremos, en primer lugar, por hablar de la presencia del sujeto y de los significados que añade a la sintaxis de la frase verbal en el poema La ceguera. Seguramente el calibre de la presencia del sujeto se puede ver mejor a través de la presencia de los verbos en la casida, que llega a veintinueve verbos. Sin embargo, esta presencia del sujeto en el poema no se produce de una sola manera y con una imagen repetida, sino que adopta diversas maneras que contribuyen a elevar el valor semántico mediante el uso del sujeto. Antes de explicar esto, hemos realizado la siguiente estadística: 


\begin{tabular}{|l|l|}
\hline Tipo de sujeto & $\mathrm{N}^{\mathrm{o}}$ de veces \\
\hline Nombre explícito & 4 \\
\hline Pronombre de $3^{\mathrm{a}}$ persona femenino singular & 5 \\
\hline Pronombre de $3^{\mathrm{a}}$ persona masculino singular & 15 \\
\hline Pronombre verbal de 3 $3^{\mathrm{a}}$ persona plural $($ waw $)$ & 1 \\
\hline Pronombre de $2^{\mathrm{a}}$ persona femenino singular & 1 \\
\hline${\text { Pronombre de } 1^{\mathrm{a}} \text { persona singular }}^{\mathrm{a}}$ & 1 \\
\hline${\text { Pronombre verbal de } 1^{\mathrm{a}} \text { persona plural (-na) }}$ & 2 \\
\hline
\end{tabular}

Esta estadística del sujeto en el poema La ceguera refleja cuán lejos está el poeta de mostrarse a sí mismo, su esencia, que es el eje de su sufrimiento a causa de la ceguera. El poeta ha querido emplear aquellos sentidos que proporciona la elisión del sujeto, su no presencia directa, para poder expresar su sufrimiento debido a la ceguera "de una manera alusiva, sencilla y muy emotiva""

Observemos la presencia del sujeto explícito en la casida que lo veremos distribuido de la siguiente manera:

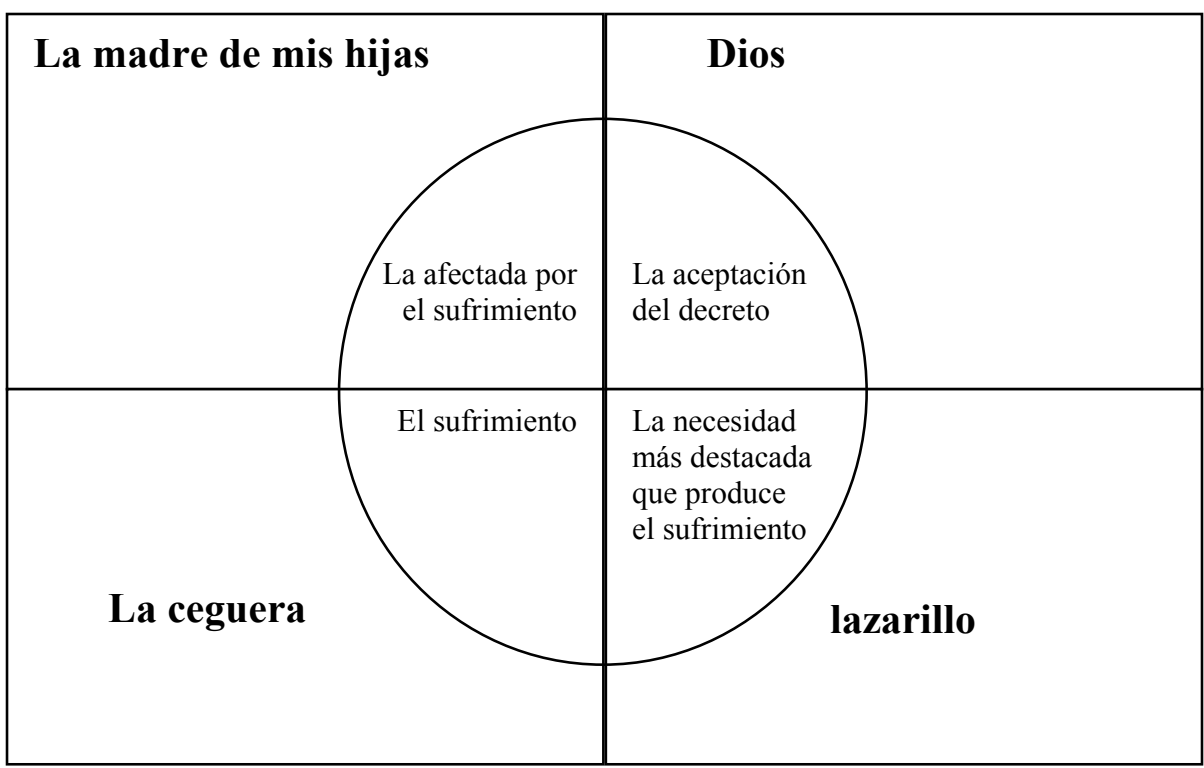

Abu 1-Majsi intenta aprovechar las posibilidades semánticas que ofrece el nombre explícito. Por ello, elige las mejores palabras que permiten formar, en caso de estar presentes en el poema, el dibujo del mapa de su sufrimiento, sin expresar los detalles de cómo ha sucedido, que es como vemos en la imagen anterior. Sin embargo, observamos que la construcción añadida en "la madre de mis hijas" tiene

\footnotetext{
${ }^{70}$ Ahmad Haykal, Al-Adab al-andalusi, p. 88.
} 
una gran participación en la profundización de la semántica poética de la casida, puesto que el poeta sustituye la referencia a la esposa de manera directa por una expresión compuesta en la que reúne a la madre con sus hijas para dibujarnos otros rasgos del alcance del sufrimiento que él soporta con su familia. Ella es una esposa débil cuya debilidad se ve aumentada por sus muchas hijas y por laausencia de un hijo que le aligere el peso de la tragedia.

Vayamos ahora a la esencia de la determinación e indeterminación de las palabras que Abu 1-Majsi intenta emplear para elevar el nivel semántico del poema. Un ejemplo de ello es lo que vemos en la expresión "la adversidad, la hostilidad" $(a l$ - $a d a)$ que le da al poema el sentido de los muchos enemigos que tiene Abu 1Majsi después de haber sufrido la ceguera. Y veamos, también, la determinación de "la tierra" (al-ard), en el verso:
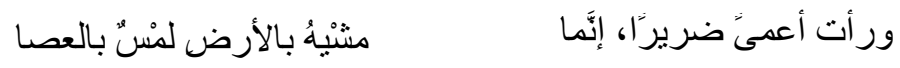

Ahora ella ve a un ciego que sólo

camina a tientas por la tierra con su báculo

En el cual, la determinación de al-ard añade al significado poético el sentido de que esta tierra es la que el poeta conoce, quien puede, al moverse un poco, caminando a tientas por la tierra, crear una relación fuerte con esa superficie conocida, como la casa, por ejemplo, o el camino a la mezquita. Sin embargo, para todo lo que no sea eso necesita de alguien que le guíe. Sobre esto se centra en los versos noveno y décimo.

También podemos observar la indeterminación de la palabra "decreto/sentencia" ( $a m r$ ) y lo que aporta al nivel semántico-poético de la casida. Está en el matla' del poema:

$$
\text { إدْ قضى اللهُ بأمر فمضى }
$$

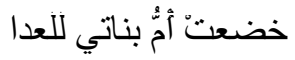

La madre de mis hijas se ha sometido a la adversidad, pues Dios dictó una sentencia que se ha cumplido

A pesar de que la palabra amr representa la desgracia tras la cual Abu 1-Majsi ha perdido la vista, evita detenerse en sus dolorosos detalles y se esfuerza en rebasarla rápidamente. Para ello recurre a indeterminarla, sin determinarla, lo cual dobla su dolor y la profundidad de su tragedia.

Por otro lado, también el que las palabras de la casida La ceguera estén en plural o en singular contribuye a dibujar la dimensión y la profundidad semántica del poema. Esto se ve claro en este verso:

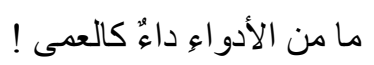$$
\text { فقؤ ادي قرحُ من قورِها }
$$

Mi corazón se desgarra cuando ella me dice: jentre todas las desgracias no hay una mayor que la ceguera!

Se puede observar en este verso que el uso del vocablo "enfermedad, mal" en singular $\left(d a^{\prime}\right)$ y en plural $\left(a d w a^{\prime}\right)$ le da al sentido poético otra dimensión. El poeta ha podido, mediante esta construcción, representar cuán grave es la ceguera, su 
dolor, frente a otros males que, aunque son muchos y variados, son insignificantes frente a la ceguera.

Miremos también la construcción como nombre de unidad del vocablo "palabra, frase" (qawla), en el siguiente verso:$$
\text { فبكت وجدًا وقالت قولة هي حرَّى بلغت مني المدى }
$$ \\ Y llora dolorida; y pronuncia palabras \\ con voz ferviente, que llegan a lo más hondo de mi ser.}

Me parece que Abu 1-Majsi quiso, mediante la construcción de la palabra qawla según la forma de un singulativo, añadir una dimensión semántica más profunda al significado de aquella sencilla palabra, recurriendo a indicar su tamaño insignificante mediante el singulativo y la indeterminación. No es una larga conversación ni un extenso diálogo que haya tenido con su esposa, sino que es una simple palabra, de composición sencilla pero de significado emotivo. Por ello, intenta intensificar este significado connotativo en el segundo hemistiquio, cuando la describe por su ardor, por su alcance profundo en el alma del poeta.

En cuanto a las características que tiene la repetición del nombre y las emotivas dimensiones semánticas que aporta al significado al que aspira conseguir el poeta, puede verse claro en las repeticiones que hace Abu 1-Majsi de la palabra "ceguera" en tres ocasiones: a'mà, ka-l- 'amà, al- 'amà, en los versos 2, 4 y 5, para confirmar la profundas impresión que le provoca esta desgracia.

\subsection{LOS SIGNIFICADOS DE LAS PARTÍCULAS}

Abu 1-Majsi puede en el poema La ceguera emplear las posibilidades semánticas de las partículas de una manera sobresaliente a la hora de dibujar los detalles del sufrimiento que le produce la desgracia de la ceguera que sufre. Ahora podemos detenernos ante las partículas más destacadas cuyo uso en la casida conforma un amplio espacio de significados connotativos. Dice Abu 1-Majsi:

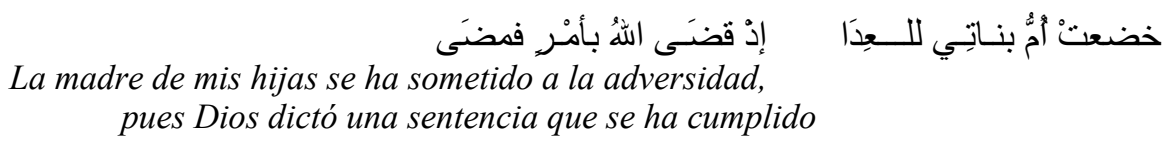

Observamos que, en le segundo hemistiquio, el poeta utiliza la partícula id para indicar el tiempo en el que ocurrió el incidente. Es como si quisiera decirnos que el momento en el que ocurrió el incidente fue rápido, fugaz. Puede que el uso de esta partícula de constitución insignificante y que hace referencia a un adverbio temporal indique, también, que el poeta no quiere recordar los detalles de este suceso doloroso. Ya hemos hablado antes de este significado connotativo al analizar el espacio semántico que conforma el nombre amr. Quizá esto mismo es lo que inspira el empleo que hace Abu 1-Majsi de la partícula $f a$ - con el verbo madà. La partícula $f a$ - nos informa de hay una sucesión inmediata y rápida, encadenándose 
los acontecimientos después de lo que le ha pasado. Abu 1-Majsi repite el uso de la partícula $f a$ - otra vez, para aprovechar el significado connotativo que proporciona dicha partícula, en el siguiente verso:

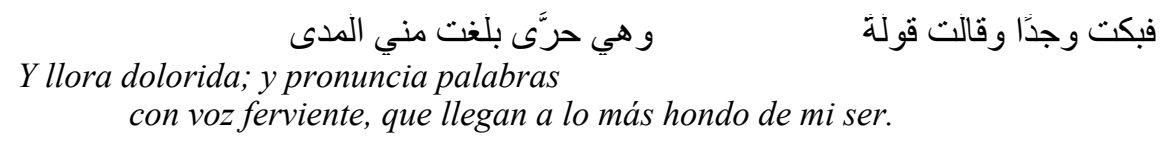

En cuanto la esposa ve la desgracia que se ha apoderado de su marido, se echa directamente a llorar, acompañando el llanto con una qawla que hiere a nuestro poeta. La partícula waw consigue dar la idea de sincronización temporal entre el llanto de la esposa y las palabras que pronuncia.

Del mismo modo, el sentido que proporciona la unión como prefijo de la partícula $b i$ - en bi-amr da un significado connotativo de la calamidad, de la ceguera, que se le ha unido al poeta, que no puede librarse de ella de ninguna manera. Podemos observar cómo el poeta se aprovecha del empleo semántico que proporciona la partícula $b i$ - en el verso siguiente:

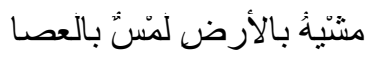

Ahora ella ve a un ciego que sólo

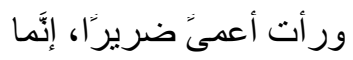

camina a tientas por la tierra con su báculo

La presencia de la partícula $b i$ - con los dos nombres, con al-ard y con al-'asa, reflejan cómo el poeta está unido a la tierra de manera permanente, teniendo que emplear el sentido del tacto para reconocer las cosas que están a su alrededor. Está unido, pegado a la tierra, cercano a ella, de manera obligatoria, para evitar los peligros. Abu l-Majsi emplea la partícula $b i$ - unida a la palabra al- 'asa en el verso anterior para representar hasta qué punto ha pasado a estar unido, pegado, al bastón, hasta el punto de que se ha convertido en un elemento importante en su vida. También vemos que intenta, después, confirmar este sentido connotativo en el verso:

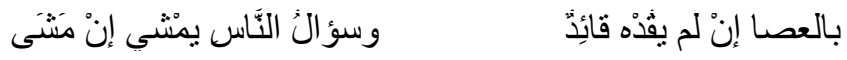

Y si no hay lazarillo que lo lleve, va con el bastón, suplicando a las gentes que lo guien, cuando quiere caminar

En cuanto a cómo evita Abu 1-Majsi mostrarse a sí mismo en el poema y cómo transforma su sufrimiento a causa de la ceguera en una experiencia humana general que sufre todo aquel que ha perdido la vista, lo hace mediante el empleo de los significados connotativos que proporciona la elisión del sujeto en la frase. Vemos que el poeta pretende, de nuevo, confirmar estos sentidos usando las partículas condicionales ida, in, haytu, en estos versos:
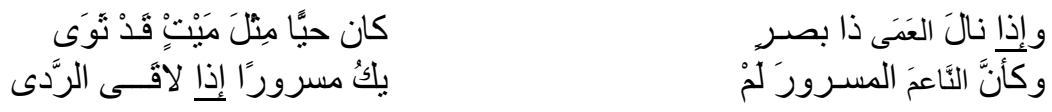

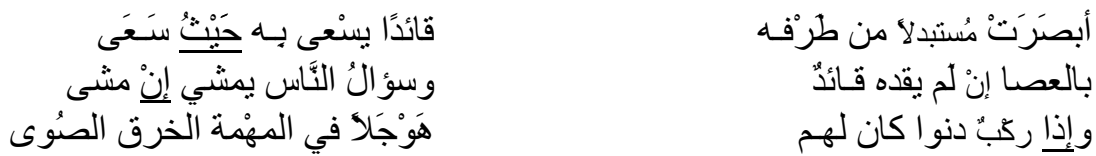

Cuando la ceguera sobreviene a un hombre que antes vio, queda-aunque vivo- como un muerto sepultado

$y$ aquel que disfruta de una vida alegre y dulce deja de estar alegre cuando se encuentra con la muerte.

Ella contempla a un hombre al que cambiaron sus ojos por un lazarillo que lo conduce a donde quiere ir y si no hay lazarillo que lo lleve, va con el bastón, suplicando a las gentes que lo guíen, cuando quiere caminar Antes, cuando venían las caravanas, era para ellas el hombre fuerte que las guiaba en el desierto interminable

El uso que hace Abu 1-Majsi de las partículas condicionales en el poema le ayuda mucho a la hora de representar lo que sufre con la ceguera, describiéndola como una experiencia humana general de todos aquellos afectados por la pérdida de la vista y por la desgracia de la ceguera. Ninguna de las partículas condicionales del poema se asocia a la propia persona del autor de una manera directa, sino que la expresión alusiva es la tónica general, participando de manera activa el espacio semántico que dibujan las partículas condicionales en este significado que desea el poeta.

\section{CONCLUSIÓN}

El dominio que tiene el poeta de sus herramientas poéticas, en especial con aquellas que se refieren a la construcción lingüística y a la ingeniería de las palabras para su creación poética, le proporcionan excelencia y riqueza para su experiencia poética. Esto es lo que observamos en la experiencia poética de Abu 1-Majsi. La casida La ceguera no es la única muestra de ello, sino que encontramos, en lo que ha quedado de su producción poética, lo que confirma este punto de vista.

En mi opinión, esta lectura refleja algunos de los significados connotativos de las palabras del poema La ceguera de Abu 1-Majsi, la excelente capacidad técnica de nuestro poeta a la hora de emplear la mayor energía semántica en las palabras usadas en este poema. La casida La ceguera se presenta en un molde técnicoartístico excepcional a través del cual las palabras canturrean las palabras y sus significados para componer una imagen técnica creativa que describe las diferentes dimensiones de la amarga experiencia del poeta con la desgracia de la ceguera. 